\title{
Usage of buildings in the life cycle of two endangered Rhinolophus species in the Mediterranean region: implications for roost protection
}

\author{
Rebecca Winter $^{1} \cdot$ Jasmin Mantilla-Contreras ${ }^{1} \cdot$ Sabine Schmidt ${ }^{2}$ \\ Received: 13 April 2019 / Revised: 1 March 2020 / Accepted: 20 March 2020 / Published online: 10 April 2020 \\ (C) The Author(s) 2020
}

\begin{abstract}
Synanthropic roosting may allow cave-dwelling bats to cope with habitat fragmentation provided that suitable buildings are sustainably protected. This study on Asinara Island, Sardinia, focuses on roost requirements in synanthropy at different life stages of two endangered bat species, Rhinolophus hipposideros and Rhinolophus ferrumequinum. We rated the roost potential of 532 buildings and compared it with actual roost usage. Microclimate was compared across different roost types and between species, and bat composition and behaviour in nurseries of $R$. hipposideros were related to roost structure and microclimate. The two species occupied $25 \%$ of structures rated as "high potential", versus $5 \%$ and $0 \%$ rated as "intermediate" and "low potential". Concerning microclimate, $R$. hipposideros preferred warmer and drier day roosts, with higher temperature fluctuations during summer, while winter, and night, roost microclimate was comparable between species. In larger, warmer, and drier nurseries, colony size and proportion of reproductive females were higher and parturition started earlier. Before parturition, roost temperatures were inversely correlated to clustering, supporting its thermoregulatory function. Mothers spent in total $50 \%$ of the night inside the nursery caring the pup. Roost microclimate, size, and location close to foraging areas may thus promote breeding success. We conclude that a structure-based rating of roost potential supplemented by species-specific microclimatic requirements constitutes a promising predictor of roost usage. Moreover, adequate buildings support the complete life cycle of $R$. hipposideros in the absence of suitable caves. Buildings thus deserve increased protection measures in fragmented Mediterranean landscapes to ensure sustainable bat conservation.
\end{abstract}

Keywords Roost evaluation $\cdot$ Horseshoe bats $\cdot$ Bat conservation $\cdot$ Microclimate $\cdot$ Synanthropic roosting

\section{Introduction}

The recent global loss of biodiversity puts a focus on effective species conservation in hot spots such as the Mediterranean basin (Myers et al. 2000; Grill et al. 2007). As habitat fragmentation is an essential driving factor for biodiversity loss (e.g., Fahrig 2003; Barnosky et al. 2011), the habitat directive protects foraging areas as well as roosting sites of species of "community interest" (92/43/EEC, Annex IV). This includes all European bat species, as they react sensitively to habitat

Rebecca Winter

winterebecca@web.de

1 Institute of Biology and Chemistry, University of Hildesheim, Universitätsplatz 1, 31141 Hildesheim, Germany

2 Institute of Zoology, University of Veterinary Medicine Hanover Foundation, Bünteweg 17, 30559 Hanover, Germany fragmentation (e.g., Walsh and Harris 1996; Hutson et al. 2001; Dietz and Kiefer 2014). Cave-dwelling species are particularly affected by habitat fragmentation as foraging areas have to be connected with adequate roosting sites, and caves are a spatially limited resource (e.g., Bontadina et al. 2000; Tournant et al. 2013; Reiter et al. 2013). Thus, fragmentation may not only destroy foraging areas but may also prevent bats to commute between foraging area and cave, so that a cave may be lost as roost. Some cave-dwelling species compensate the absence of suitable caves by synanthropic behaviour and use buildings as roosts (e.g., Kunz 1982; Voigt et al. 2016). This roosting strategy may reduce commuting distance (Knight and Jones 2009), and may allow bats to explore new habitats (Fenton et al. 2002; Mazurska and Ruczyński 2008), as well as to extend their geographical range (Fenton 1970; Kunz and Reynolds 2003). The identification and characterization of these roost alternatives is thus essential in order to integrate buildings into conservation measures and is the central focus of the present study. 
The lesser, and the greater, horseshoe bat, Rhinolophus hipposideros and Rhinolophus ferrumequinum, are two cave-dwelling species "whose conservation requires the designation of special areas of conservation" (92/43/EEC, Annex II). The IUCN 2016 estimated decreasing population trends for both species (Taylor 2016; Piraccini 2016). With their high site fidelity (Gaisler 1963; Flanders and Jones 2009) and low commuting distance (Duvergé and Jones 1994; Bontadina et al. 2002), both species are particularly threatened by the loss of adequate roosts close to their foraging areas (see Dietz and Kiefer 2014). Roosts serve different functions in the life cycle of the two species; i.e., they are used for resting during daytime, breeding and nursing the pups, resting between foraging bouts during the night, and hibernating (Dietz et al. 2007). The importance of microclimate has been studied for some roost types of $R$. hipposideros (e.g., nurseries: Kayikcioglu and Zahn 2004; winter roosts: Zukal et al. 2005) and R. ferrumequinum (e.g., nurseries: Maltagliati et al. 2013; winter roosts: Ransome 1971). These roosting requirements may be met by buildings exhibiting particular structural characteristics. Indeed, the use of buildings even allowed the two species to extend their distribution range in Central Europe (Gaisler 1963; Dietz et al. 2007). Synanthropic roosting of the two species has also been reported from their main distribution range, the Mediterranean basin (Mucedda and Pidinchedda 2010; Maltagliati et al. 2013; Lisón et al. 2013), which emphasizes the urgency of protecting adequate buildings in this region.

However, the request profile for synanthropic roosts in the different stages of the life cycle of the two species still needs clarification. Therefore, we evaluated buildings and investigated their use as different roost types by the two Rhinolophus species occurring in Asinara Island National Park, Sardinia. The island is an ideal region for a case study as it has no natural caves suitable for Rhinolophus and provides a high number of abandoned buildings, and both species were known to roost inside them (Winter et al. 2017). Moreover, direct disturbance, e.g., by light pollution or construction work, or effects of a given agricultural use affecting insect abundance, do hardly interfere with roost usage on this barely inhabited and no longer cultured island. We focused on the following questions:

1. Can structural characteristics of buildings be used to predict their potential as Rhinolophus roosts?

2. Which structural and microclimatic conditions satisfy the requirements of a given species on its different roost types?

3. How do life cycle traits affect the requirements on nursery roosts?

We first rated roost potential based on predefined structure characteristics. Then, we compared structure characteristics, and microclimate, with actual roost usage so that differences and similarities between species, and roost types, become apparent. Finally, bat composition and behaviour in several nursery roosts of $R$. hipposideros were monitored during a breeding season and related to structural and microclimatic characteristics. Thereby, we gained information about roost switching, clustering, the influence of microclimate, and the usage of nurseries during the night.

\section{Material and methods}

\section{Study area}

The study was conducted in the Asinara Island National Park (SCI: ITB010082; SPA: ITB010001) located at the north-west coast of Sardinia $41^{\circ} 3^{\prime} \mathrm{N}, 8^{\circ} 15^{\prime} \mathrm{E}$ (Fig. 1). The off-shore island has an area of $52 \mathrm{~km}^{2}$ and elevations range from 0 to $408 \mathrm{~m}$ (a.s.1.). Before being designated as a national park in 1997, Asinara served intermittently as a prison island and was inhabited for centuries (Massida 2008). As a result, the island is characterized by a high number of abandoned buildings in different states of decay and the presence of many feral ungulates. Influenced by the grazing pressure, the landscape mostly consists of typical Macchia and Garrigue. The forested area in the northern part of the island only comprises about $0.2 \mathrm{~km}^{2}$ (Fig. 1). Freshwater bodies are rare - only four ponds are perennial, providing year-round water. Main threats for bats on the island are stray cats and flying predators such as owls, as well as the restoration of buildings for touristic use.

\section{Surveys of buildings and roost identification}

Based on a high-resolution ortho-photo, all buildings on the island were detected using ArcGIS (version 10.1, ESRI, Redlands, CA) resulting in 532 survey points, which were inspected from May to August 2014. Buildings comprised different types of man-made structures, such as residential houses, prison buildings, or cisterns. We classified a building as "above ground" if its main part was above ground, "below ground" if its main part was subterranean, and "ruin" if the walls and roof did not form an enclosed compartment. The potential of each building as Rhinolophus roost was evaluated based on four different criteria; each was rated with a score of $0,0.5$, or 1 as follows.

1. Entrance: 0, no entrance/entrance difficult for bats to enter on the wing (e.g., narrow crevices and holes with diameters of less than $5 \mathrm{~cm}$ ) and to perform typical "light-sampling" (Twente 1955; DeCoursey and DeCoursey 1964); 0.5 , entrance easy to enter for bats but also allows flying predators to invade; 1 , entrance as above but with limited access for flying predators, e.g., if entrance is partly 
Fig. 1 Location of Asinara Island with forested area and water bodies. The circles represent buildings that contain Rhinolophus roosts. Nurseries studied in detail are labelled

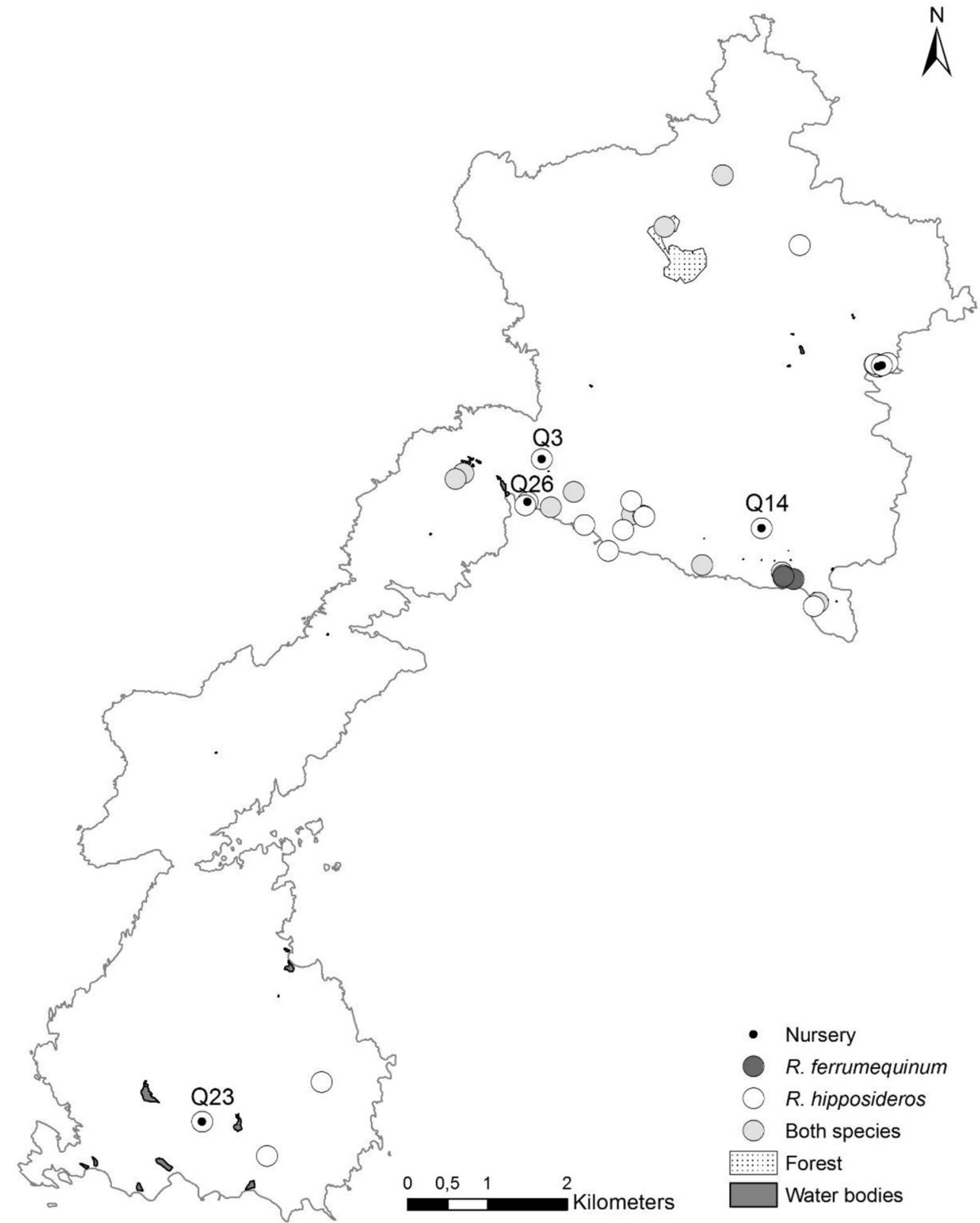

covered by vegetation or metal bars, or is complicated to enter from the top.

2. Light: (measured during daytime) 0 , similar light conditions inside and outside; 0.5 , light dimmed, torch facilitates exploring the structure; 1 , building completely dark.

3. Weather protection: 0 , ruin; 0.5 , parts of structure not wind and water proof; 1 , structure wind and water proof. Please note that criteria "light" and "weather protection" are not redundant as e.g. intact glass windows with and without shutters lead to different light scores but an identical weather protection score.

4. Available perching height: 0 , ceiling continuously lower than $120 \mathrm{~cm}$ (Walmsley et al. 1978; Zajac et al. 1981) so that perching bats may be reached by cats (Ancillotto et al. 2013); 0.5 , ceiling in some parts lower than $120 \mathrm{~cm}$ but bats can choose higher perching places; 1 , ceiling continuously higher than $120 \mathrm{~cm}$.

Buildings were qualified as "low potential" if the entrance score was 0 or the sum of scores was less than 2, as "intermediate potential" for scores of 2 and 2.5, and as "high potential" for scores of 3 and above.

Bat presence was established by visual inspections, outflight observations, and call recordings. In the latter case, a bat detector (EM3+, Wildlife Acoustics, Maynard, MA, USA) set to automatic trigger mode was placed inside a 
potential roost for 2 days to check for bat presence. If Rhinolophus bats were present, during day time or at night, the building was defined as "used". Additionally, species, as well as number of individuals, were listed. Buildings that were empty at first inspection but contained bat faeces were classified as "used" if Rhinolophus bats were present at subsequent day or night inspections. As a single building may be used by different species, or at different periods (see the "Roost monitoring" section), it may comprise more than one roost.

To asses building evaluation, we compared it with actually used buildings using a Pearson-chi ${ }^{2}$ test with expected values based on the distribution of type, and potential, of buildings. With binomial tests, we checked for preferences of a species to roost in structures "above ground" or "below ground" for a respective roost type with expected values adjusted to the given number of structures above and below ground. Statistical testing was performed with Statistica (version 6, StatSoft Inc., Tulsa, USA) here, and in all subsequent analyses, using a significance level of $5 \%$.

\section{Roost monitoring}

Roosts identified in 2014 were monitored from January to September 2015. Species as well as number of individuals were recorded by visual inspections in intervals of about 9 days. In four suspected nursery roosts, automated photo recordings were done to avoid disturbances during the breeding season (see the "Monitoring and behaviour in $R$. hipposideros nursery roosts" section). Two more nurseries were confirmed, one via inspection at night which revealed pups left behind, another one via mist netting of lactating females during outflight. In total, we defined seven roost types (see Table 1). Data loggers (iButton, ThermoHygrochron, Maxim Inc., San Jose, CA, USA) monitored temperature and relative humidity once per hour in 25 randomly selected buildings used by Rhinolophus, and at three outside locations on the island, for the whole monitoring period. Microclimatic data were obtained for 30 roosts of $R$. hipposideros and 14 roosts of $R$. ferrumequinum. Daily mean values were calculated and temperature excursions were characterized by the daily standard deviation. Furthermore, we used repeated-measures general linear models (RMGLM) with weekly mean values of microclimate as repeated measures and roosts as groups to examine microclimatic differences for a given roost type across species, and between roost types within a species. Roosts shared by both species were counted for each of them. The microclimate between different roost types was compared for corresponding time periods. Microclimatic data for night roosts were considered only if the roost was occupied exclusively during the night.

\section{Monitoring and behaviour in $R$. hipposideros nursery roosts}

Four nursery roosts were observed with automatic photo cameras (DÖRR Snapshot Mini Black, Germany) from April to August 2015. Each camera took a photo every $20 \mathrm{~min}$ with invisible IR black vision LED light to avoid disturbances of the bats. Short video control recordings revealed that the bats did not react when photos were taken. To ensure an optimal coverage of these roosts, two up to four cameras were installed inside a nursery focusing on perching sites, identified by faeces. Two other nurseries were unsuitable for camera monitoring due to their inaccessibility, or a building structure that prevented a complete roost coverage by cameras; of these nurseries, only the number of adult bats was counted regularly via outflight observations.

Throughout the observation period, the photos of every third day were examined and individuals were counted. If the first pup was detected, the pictures of the previous 2 days were also analysed to determine the date of first parturition. Starting from this date, we analysed each day until no more pups were born. We compared the number of adults, parturition dates, the number of pups, the proportion of reproductive females (calculated with the mean number of adults present during the period of parturitions), and microclimatic conditions across nursery colonies, and we correlated the maximum number of adults in a roost with roost size using Spearman's rank correlation.

In addition, all photos of nursery Q3 from 29 May to 29 June were analysed using a custom-made software (by Dr. J. Pillat) in Visual Basics (Microsoft Corp, Redmond, WA). To study perching behaviour during daytime, we distinguished adults perching "separately" from those perching in "cluster",
Table 1 Definition of roost types based on occupation period and way of usage. Please note that, in a given occupation period, all roost type definitions are mutually exclusive; e.g., a nursery roost is not counted as any other day roost type

\begin{tabular}{lll}
\hline Roost type & Definition & Occupation period \\
\hline Winter roost & Day roost during coldest period & Winter, Jan-Mar \\
Regular day roost & Occupied in more than 50\% of inspections & Summer, Apr-Sep \\
Temporary day roost & Occupied in less than 50\% of inspections & Summer, Apr-Sep \\
Night roost & Occupied during the night & Summer, Apr-Sep \\
Nursery roost & Day roost used for birth and pup raising & Breeding, May-Jul \\
Temporary nursery & Temporary occupied by mother and pup & Breeding, May-Jul \\
Not monitored & Bats present; monitoring not practicable & - \\
\hline
\end{tabular}


i.e., with body contact. The effects of temperature, the date relative to parturition, and the number of pups were correlated with perching behaviour (Spearman's rank correlations). If more than one parameter was significantly correlated, we performed stepwise forward multiple regressions with these parameters. To analyse roost usage during the night, we determined the presence of reproductive females, defined by a bat in body contact to a pup, and compared it with the presence of non-mothers using a Mann-Whitney $U$ test. Finally, we measured the mother-pup contact time at night in two nurseries in which only one perching site was available to the bats (Q3 and Q14) to determine the presence-absence pattern of lactating females. Since differentiation of individual mother-pup pairs was not possible from the photos, we analysed nights at the beginning of the parturition period in which only one pup was present in a given roost to ensure that observations per night were from the same mother-pup pair. This situation was given for, in total, eight nights (three nights of one pup in Q3, five nights of one pup in Q14). After the outflight of the colony, the pup was left behind, however visited and covered by its mother several times during the night, so that absence bouts of the mother alternated with contact times. General presenceabsence patterns were calculated based on mean mother-pup contact times.

\section{Results}

\section{Evaluation of buildings and identified roosts}

Of 532 buildings on Asinara, 473 were accessible, and were evaluated and checked for Rhinolophus roosts. We rated 108 buildings as "high potential", 171 as "intermediate potential", and 194 as "low potential" (Table 2).

Rhinolophus bats were found in 36 buildings across the island in 2014. Roost monitoring in 2015 revealed that 23 buildings were occupied exclusively by $R$. hipposideros, two by $R$. ferrumequinum, and 11 by both species (Fig. 1). Nine of these buildings served as roosts in summer as well as in winter. Preferences for a building type were obvious for $R$. hipposideros which, in winter, occupied roosts "below ground" significantly more frequent than those "above ground" ( $p=0.003, n=14)$. In both seasons, roost changes occurred between consecutive inspections. In total, we identified 64 roosts; i.e., a given building often provided several roosts of different types or for different species (Fig. 2). In the eleven buildings used by both species, they shared a day roost in only $5 \%$ of the summer and $10 \%$ of the winter roost inspections; night roost sharing was never observed. Roosts typically contained one to four individuals. We found six nurseries of $R$. hipposideros which, in general, hosted a higher number of individuals (see "Roosting ecology and behaviour in R. hipposideros nurseries" section) than other day roosts. In contrast, no nursery of $R$. ferrumequinum was detected.

Concerning the evaluation criteria, 28 of the 36 occupied buildings were rated "high potential" and eight "intermediate potential" (Table 2); i.e., $25 \%$ of the "high potential" and only $5 \%$ of the "intermediate potential" buildings were used. Buildings rated as "high potential" were significantly preferred and those rated as "low potential" avoided, whereas those of "intermediate potential" were used as expected (chi ${ }^{2}$ test, see Table 2). A comparison of the 80 unused, versus 28 used, buildings of "high potential" revealed no striking differences with respect to the evaluation criteria (Table 3); in both groups, some buildings reached the maximum total evaluation score and no criterion was rated zero. Buildings used as nurseries turned out to have the highest total evaluation scores and were the only roost type for which "entrance" score amounted to 1 ; around $70 \%$ of the other day roosts and $60 \%$ of winter roosts were accessible for flying predators. "Perching height" reached a high score for all roost types whereas "light" and "weather protection" showed considerably lower scores for night roosts compared to other roost types. Indeed, seven of the eight used buildings of "intermediate potential" served as night roosts.
Table 2 Total and used number of accessible structures evaluated as "high", "intermediate", or "low" roost potential. Chi ${ }^{2}$ test (overall total $\chi^{2}$ $\mathrm{df}=8$, category total $\chi^{2} \mathrm{df}=2$ ) was used to check if Rhinolophus bats preferred structures of any evaluation category. Expected values were adjusted proportionally to the total number of a given structure type and evaluation category

\begin{tabular}{|c|c|c|c|c|c|c|c|c|}
\hline \multirow[t]{2}{*}{ Structure type } & \multicolumn{2}{|c|}{ High potential } & \multicolumn{2}{|c|}{ Intermediate potential } & \multicolumn{2}{|c|}{ Low potential } & \multicolumn{2}{|l|}{ Total } \\
\hline & Used & Total & Used & Total & Used & Total & Used & Type \\
\hline Above ground & 18 & 69 & 7 & 149 & 0 & 70 & 25 & 288 \\
\hline Under ground & 10 & 39 & 1 & 20 & 0 & 21 & 11 & 80 \\
\hline Ruin & 0 & 0 & 0 & 2 & 0 & 103 & 0 & 105 \\
\hline Total & 28 & 108 & 8 & 171 & 0 & 194 & 36 & 473 \\
\hline$\chi^{2}$ & $47.82 *$ & & 1.98 & & $14.74 *$ & & $64.53 *$ & \\
\hline
\end{tabular}




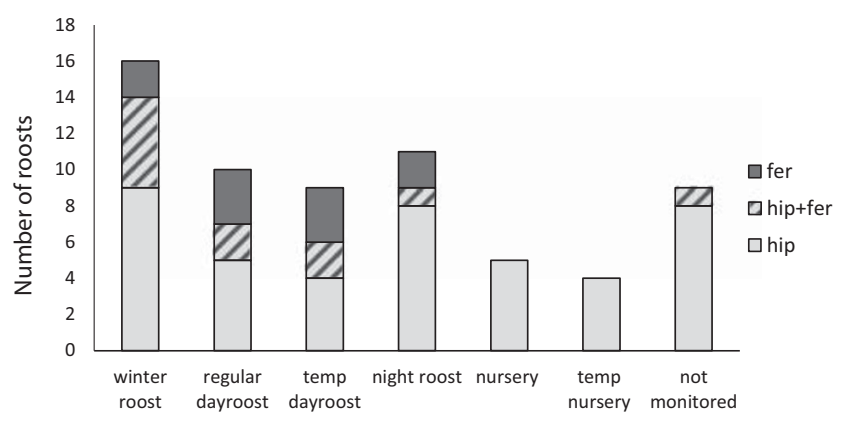

Fig. 2 Distribution of Rhinolophus roost types on Asinara. Numbers per roost type are given for $R$. hipposideros (hip), R. ferrumequinum (fer), and both species (hip+fer). Due to multiple roost usage by the two species, or the usage of a building for different roost types, the total number of roosts $(n=64)$ is higher than the number of used buildings $(n=36)$. Note that one nursery of $R$. hipposideros was inaccessible to humans and was therefore listed as "not monitored"

\section{Microclimatic conditions}

Grand mean temperature of roosts varied between 21.0 and $24.8^{\circ} \mathrm{C}$ in summer and amounted to about $11.5^{\circ} \mathrm{C}$ in winter (for details, see Table 4), while outside temperature had a grand mean of $22.7{ }^{\circ} \mathrm{C}$ in summer and $11.1{ }^{\circ} \mathrm{C}$ in winter. Grand means of daily fluctuations were between 0.3 and $1.3^{\circ} \mathrm{C}$ in summer roosts, and between 0.3 and $0.5^{\circ} \mathrm{C}$ in winter roosts. Relative humidity in roosts showed grand means between 65 and $84 \%$ in summer, and between 86 and $93 \%$ in winter. Outside, grand means were $70 \%$ in summer and $80 \%$ in winter. While roost temperatures in winter were similar to the outside temperature for both species, summer day roosts of $R$. hipposideros showed higher temperatures, and those of $R$. ferrumequinum lower temperatures, compared to the outside temperature (Fig. 3).

Whereas the microclimate for winter, and night, roosts showed no differences between the two species, we found significant differences for regular day roosts (Table 4A). First, $R$. hipposideros used warmer and drier regular day roosts than $R$. ferrumequinum. Temperatures of the day roost regularly used by both species were in the overlap range of both species (Fig. 4). Secondly, daily temperature fluctuation was significantly higher in regular day roosts of $R$. hipposideros than of $R$. ferrumequinum. Concerning the microclimate of different roost types within a species (Table 4B), night roosts used by $R$. hipposideros were colder and drier than regular day roosts and daily temperature fluctuations were higher. Comparing regular day roosts with temporary ones, the latter were colder and more humid. However, we found no differences between nurseries and regular day roosts. Night roosts and regular day roosts of $R$. ferrumequinum had similar temperatures and relative humidity but the daily temperature fluctuation was higher in night roosts; regular day roosts were warmer and drier, and had a lower temperature fluctuation than temporary ones.

\section{Roosting ecology and behaviour in $R$. hipposideros nurseries}

The number of individuals differed between nurseries and also inside a given nursery across days. The maximum colony sizes varied between 9 and about 50 adults (Table 5). Colony size was directly correlated with roost size (Spearman's $R^{2}=0.88$ ). Total parturition period lasted from 14 June 2015 to 1 July 2015. If more than one pup was born in a given roost, the period of parturitions was between 8 and 15 days. The proportion of reproductive females in nurseries was between 35 and $72 \%$. The nursery with the earliest parturition and the highest proportion of reproductive females was one of the warmest and driest roosts. In contrast, the nursery with the latest onset of parturitions, the smallest proportion of reproductive females, and the smallest number of adults was the coldest and most humid roost (Table 5). Parturitions occurred generally during daytime with the exception of a parturition just before sunrise. In observed nurseries, females with pups generally stayed in the same roost during the parturition period. Only the mother in the coldest and most humid roost left the roost with her pup during the first night after parturition; however, a mother-pup pair came back to this roost in the following night. Since the number of pups inside the other observed nurseries remained constant, we suppose this mother had used a temporary nursery. Additionally, we observed that, during daytime, mothers of Q23 generally used the part of the cistern equipped with cameras but frequently brought their pup to another place for some hours of the night. As this roost consisted of two identically structured subterranean parts with separate entrances, we assumed that pups were brought to this neighbouring part. Nightly visual inspections of this part in August confirmed our assumption since some of the young bats were found perching there.

The analysis of perching behaviour during daytime in one of the nurseries revealed a negative correlation
Table 3 Evaluation scores of used versus empty buildings with "high roost potential"

\begin{tabular}{lllll}
\hline & Entrance & Light & Weather & Available perching height \\
\hline Grand mean of used buildings $(n=28)$ & 0.73 & 0.89 & 0.89 & 0.95 \\
Grand mean of empty buildings $(n=80)$ & 0.68 & 0.77 & 0.95 & 0.94 \\
\hline
\end{tabular}


Table 4 Differences of microclimate in roosts used by $R$. hipposideros (R. hip) and R. ferrumequinum (R. fer) (A) and between different roost types of the same species (B). $n$ indicates the respective roost numbers. Mean values with standard deviation of temperature, daily fluctuation, as well as relative humidity are shown. For statistical analyses, weekly mean values over time of each roost were considered (GLM, ANOVA with groups, and repeated measures). Significant differences between the compared microclimatic parameter are marked bold and with "+" for significantly higher and with "." for significantly lower. No significant differences are shown by "o". Please note that all statistical comparisons refer to corresponding time periods

\begin{tabular}{|c|c|c|c|c|c|c|}
\hline & Subject & $n$ & Compared between & Temperature $\left({ }^{\circ} \mathrm{C}\right)$ & Daily fluctuation $\left({ }^{\circ} \mathrm{C}\right)$ & Rel. humidity (\%) \\
\hline \multirow[t]{6}{*}{ A } & \multirow[t]{2}{*}{ Day roost } & 6 & R. hip & $24.5 \pm 4.9+$ & $0.8 \pm 0.2+$ & $76.5 \pm 12.8-$ \\
\hline & & 4 & R. fer & $21.0 \pm 4.7-$ & $0.3 \pm 0.5-$ & $84.0 \pm 11.5+$ \\
\hline & \multirow[t]{2}{*}{ Winter roost } & 12 & R. hip & $11.6 \pm 1.1 \mathrm{o}$ & $0.3 \pm 0.3$ o & $92.7 \pm 10.7 \mathrm{o}$ \\
\hline & & 6 & R. fer & $11.5 \pm 1.1 \mathrm{o}$ & $0.5 \pm 0.4 \mathrm{o}$ & $85.6 \pm 12.8 \mathrm{o}$ \\
\hline & \multirow[t]{2}{*}{ Night roost } & 3 & R. hip & $23.9 \pm 4.6 \mathrm{o}$ & $1.3 \pm 0.6 \mathrm{o}$ & $66.8 \pm 6.8$ o \\
\hline & & 1 & R. fer & $24.2 \pm 4.7 \mathrm{o}$ & $1.3 \pm 0.4 \mathrm{o}$ & $65.0 \pm 6.7 \mathrm{o}$ \\
\hline \multirow[t]{10}{*}{ B } & \multirow[t]{6}{*}{ R. hip } & 3 & Night roost & $23.9 \pm 4.6-$ & $1.3 \pm 0.6+$ & $66.8 \pm 6.8-$ \\
\hline & & 6 & Regular day roost & $24.5 \pm 4.9+$ & $0.8 \pm 0.2-$ & $76.5 \pm 12.8+$ \\
\hline & & 4 & Temporary day roost & $21.4 \pm 4.8-$ & $0.5 \pm 0.6 \mathrm{o}$ & $84.1 \pm 13.6+$ \\
\hline & & 6 & Regular day roost & $24.5 \pm 4.9+$ & $0.8 \pm 0.2 \mathrm{o}$ & $76.5 \pm 12.8-$ \\
\hline & & 5 & Nursery & $23.2 \pm 2.8 \mathrm{o}$ & $1.0 \pm 0.6 \mathrm{o}$ & $73.4 \pm 11.1 \mathrm{o}$ \\
\hline & & 6 & Regular day roost & $23.6 \pm 2.8 \mathrm{o}$ & $0.9 \pm 0.6 \mathrm{o}$ & $80.4 \pm 12.5 \mathrm{o}$ \\
\hline & \multirow[t]{4}{*}{ R. fer } & 1 & Night roost & $24.2 \pm 4.7 \mathrm{o}$ & $1.3 \pm 0.4+$ & $65.0 \pm 6.7 \mathrm{o}$ \\
\hline & & 4 & Regular day roost & $21.0 \pm 4.7 \mathrm{o}$ & $0.3 \pm 0.5-$ & $84.0 \pm 11.5 \mathrm{o}$ \\
\hline & & 3 & Temporary day roost & $24.8 \pm 5.0+$ & $1.0 \pm 0.6+$ & $80.8 \pm 14.5-$ \\
\hline & & 4 & Regular day roost & $21.0 \pm 4.7-$ & $0.3 \pm 0.5-$ & $84.0 \pm 11.5+$ \\
\hline
\end{tabular}

between the mean number of adults in cluster and roost temperature $\left(R^{2}=-0.52\right)$ for the total observation period. When discriminating between the period "before first parturition" and "after first parturition", temperature was the only factor explaining perching behaviour before first parturition $\left(R^{2}=-0.56\right)$; i.e., higher temperatures were correlated with less clustering. However, after first parturition, the number of pups explained perching behaviour $\left(R^{2}=-0.81\right)$; i.e., with an increasing number of pups, less adults perched in cluster. During
Fig. 3 Roost temperature relative to outside temperature in regular winter (Jan-Mar) and summer (Apr-Sep) day roosts of R. hipposideros (hip), R. ferrumequinum (fer), and both species (hip+fer). Each symbol represents a monthly mean temperature difference of a given roost. Data stem from 8 hip, 2 fer, and 4 hip+fer roosts in winter, and 5 hip, 3 fer, and 1 hip+fer roost in summer. Vertical lines indicate the total temperature deviation range per species group; their medians are connected by lines

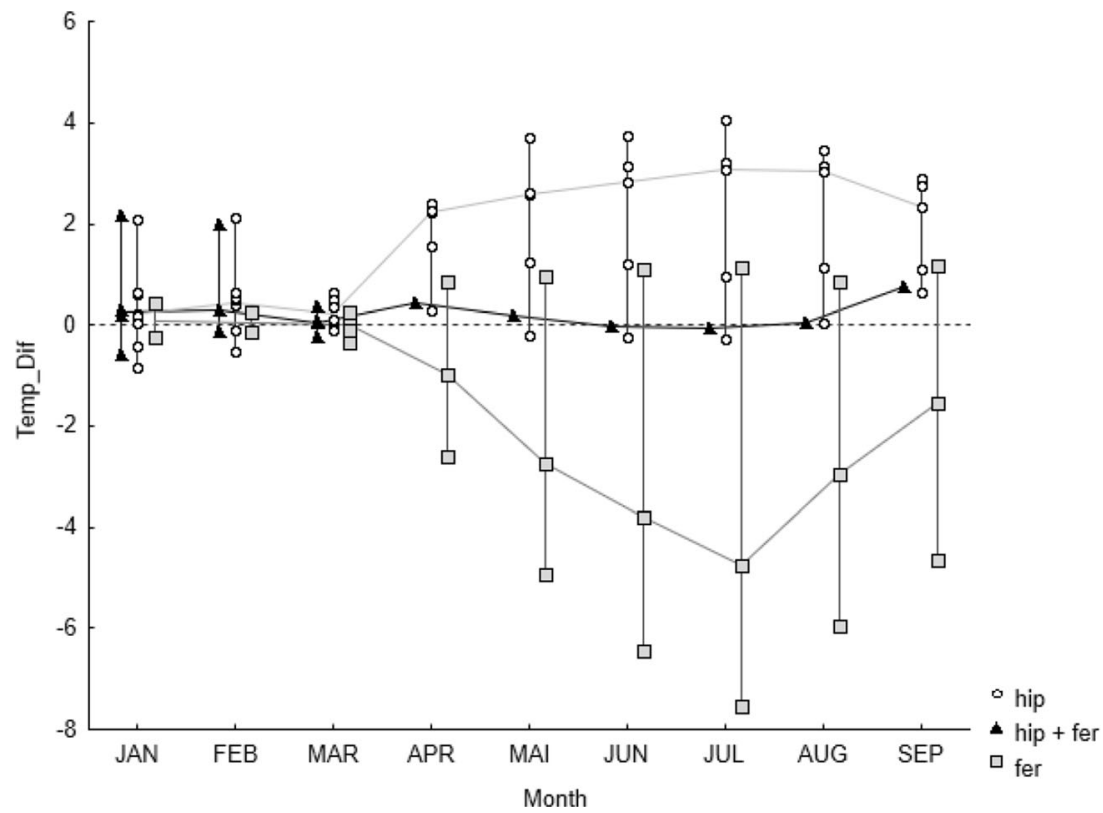




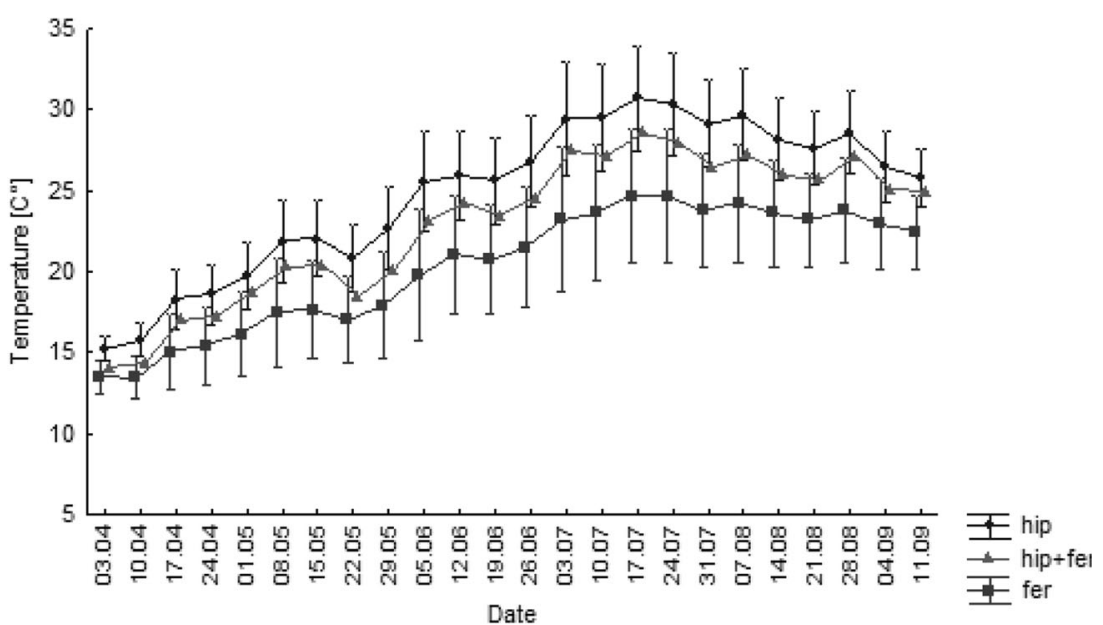

Fig. 4 Weekly mean values of temperature in regular day roosts. The date indicates to the middle of the respective week. Whiskers show maximum and minimum weekly mean values of roosts from $R$. hipposideros (hip, 5 roosts), R. ferrumequinum (fer, 3 roosts), and both species (hip+fer, 1

night, the presence of reproductive females and nonreproductive females differed, with reproductive females present on $48 \%( \pm 6.7 \%)$ and non-reproductive females present on only $21 \%( \pm 13 \%)$ of the photos per night.

Finally, the camera monitoring in the four nurseries revealed that reproductive females always flew out with the majority of the colony at dusk and returned at dawn. The analysis of mother-pup contact time in two nurseries throughout the night showed that the females, monitored in the first week after parturition, exhibited four ( $n=6$ nights) or three absence bouts ( $n=2$ nights, see Fig. 5). In the three-absence-bout pattern (Fig. 5b), the initial absence-bout and last absence-bout were longer compared with the four-absence-bout pattern (Fig. $5 a)$. Thus, in both patterns, mothers were half of the night absent (213 min, pattern a and $200 \mathrm{~min}$, pattern b) and half of the night present, caring the pup (207 min, pattern a and $220 \mathrm{~min}$, pattern b).

Table 5 Attributes of nursery roosts. For nurseries without camera observations (Q15 and Q18), only the maximum number of individuals is given, counted via outflight observations. Mean number of adults was calculated using number of adults during the total parturition period (14 June-1 July) and proportion of reproductive females (repr. females) using the number of pups and the mean number of adults; note that the $50 \%$ roost). As only one shared roost was monitored with microclimate, no minimum and maximum, but exact weekly mean values of this roost are given. For statistics (see Table 4), the shared roost counted for each species

\section{Discussion}

In the present study, both Rhinolophus species used buildings as alternatives to caves, for various roost types. Buildings were even sufficient to support the complete life cycle of $R$. hipposideros on Asinara. We showed that structural criteria are useful indicators for assessing the potential of a building as Rhinolophus roost. However, the particular usage reflected species- and roost type-specific preferences for roost microclimate. Roost size and microclimate were of special importance for reproductive females. In sum, this study underlines the importance of an integration of buildings into sustainable bat conservation concepts in the Mediterranean (cf. Marnell and Presetnik 2010; Lisón et al. 2013). The following discussion relates the specific synanthropic roosting conditions, and the specific requirements met for nurseries, on Asinara to those encountered in Central Europe and the Mediterranean, and derives conservation measures implied by the above results.

repr. females in nursery Q14 is based on one pup in a roost and only two adults. Microclimate was measured during breeding season from May to July and temperature (Temp.) gives mean values with standard deviation in ${ }^{\circ} \mathrm{C}$ and relative humidity (Rel. humidity) gives mean values with standard deviation in \%. Part parturition

Nursery Roost area Max. no. of adults Mean no. of adults Part. onset Part. period No. of pups Repr. females Temp. $\left({ }^{\circ} \mathrm{C}\right)$ Rel. humidity $(\%)$

\begin{tabular}{lllccccccc}
\hline Q14 & $4 \mathrm{~m}^{2}$ & 9 & 2 & 23.06 & 1 day & 1 & $(50 \%)$ & $21.6 \pm 2.1$ & $92.0 \pm 2.8$ \\
Q23 & $25 \mathrm{~m}^{2}$ & 25 & 18 & 14.06 & 15 days & 13 & $72 \%$ & $24.8 \pm 2.6$ & $65.3 \pm 5.9$ \\
Q26 & $90 \mathrm{~m}^{2}$ & 42 & 32 & 17.06 & 14 days & 12 & $38 \%$ & $23.3 \pm 2.5$ & $69.4 \pm 4.4$ \\
Q3 & $10 \mathrm{~m}^{2}$ & 24 & 20 & 26.06 & 8 days & 7 & $35 \%$ & $24.7 \pm 2.6$ & $64.8 \pm 4.7$ \\
Q15 & $107 \mathrm{~m}^{2}$ & 50 & - & - & - & - & - & - & - \\
Q18 & $43 \mathrm{~m}^{2}$ & 20 & - & - & - & - & - & - \\
\hline
\end{tabular}




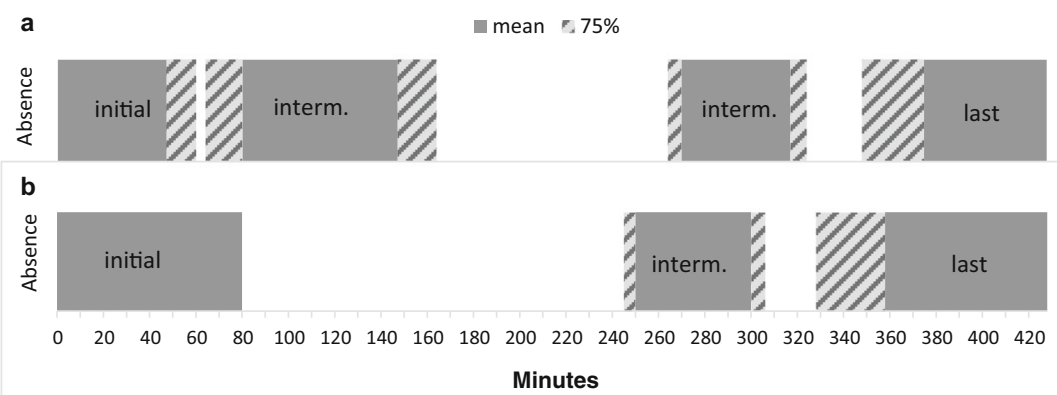

Fig. 5 Absence bout pattern with two intermediate absence bouts (a) and one intermediate absence bout (b). Calculation was based on observations of a single pup per roost in (a) six and (b) two nights after parturition.

\section{Implications of roost choice}

During summer, we found inter-specific differences in roost microclimate. $R$. hipposideros preferred warmer roosts than its heavier congener $R$. ferrumequinum. Moreover, roosts of $R$. ferrumequinum were better insulated; i.e., temperature as well as daily temperature fluctuation was low, and thus humidity remained relatively high. These results support the assumption of McNab (1974) who postulated a negative correlation between roost temperature and body weight.

Night roosts of both species differed from day roosts by giving less protection against light, predators, and weather, which was also reflected in higher daily temperature fluctuations. The function of this roost type, namely resting and digesting between foraging bouts (e.g., Shiel et al. 1999; Ormsbee et al. 2007) with a minimized distance to foraging sites (Knight and Jones 2009; Downs et al. 2016), may explain why less protected roosts were accepted at night. The fact that we did not observe night roosts shared between the two species may thus be accounted for by reduced structural and microclimatic requirements leading to a large choice of suitable buildings used during a part of the night only. On the other hand, differences in foraging habitat preferences, and ranges, of the two species (Flanders and Jones 2009; Bontadina et al. 2002) may have prevented a use of common night roosts.

A stable microclimate turned out to be an important roost trait for cave-hibernating R. hipposideros (Zukal et al. 2005). In the present study, both species hibernated in buildings of nearly identical microclimate. Roosts had mean temperatures similar to outside but much lower temperature fluctuations. These conditions have been suggested to be energetically favourable when bats wake up from hibernation to forage (Ransome 1968, 1971), which regularly occurs at mild temperatures (e.g., Avery 1985; Park et al. 2000), as we found them in our study area (Winter et al. 2017). Interspersed foraging bouts as well as an adaptation to ambient temperature during different phases of hibernation (Ransome 1968, 1971) may explain why individuals changed winter roosts or
Minutes of absence bouts with 75 th percentiles in a: initial $=47(+13)$, first intermediate $=67( \pm 16)$, second intermediate $=47( \pm 7)$, last $=53( \pm$ 27); in b: initial $=80( \pm 0)$, intermediate $=50( \pm 6)$, last $=70(-30)$

perching sites between consecutive inspections. Since Rhinolophus bats usually perch free-hanging and separate, hibernating bats are easily attackable by predators. Yet, predator protection at entrances of many winter roosts was evaluated low in our study, confirming the use of exposed hibernation perches reported from caves (Daan and Wichers 1968; Zukal et al. 2005). This suggests that predator protection is less important than adequate microclimate for the choice of hibernation sites by Rhinolophus bats and implies that creating better protected hibernation roosts is an important requirement for conservation programs.

\section{Roosting ecology of nurseries}

The proportion of reproductive females in nurseries in the present study coincided with those from Central Europe, which varied between 40 (Schofield 1996; Reiter 2004a; Bontadina et al. 2000) and 74\% (Gaisler 1966), confirming successful synanthropic roosting of $R$. hipposideros in the Mediterranean region.

Nurseries and regular day roosts showed a similar microclimate in our study. However, all nurseries provided secured entrances which may constitute a crucial factor for the survival of the non-fledged juveniles left behind in the nursery during the night. Across nurseries, higher temperatures correlated with an earlier onset of parturition, confirming previous findings in various geographic regions (e.g., Schofield 1996; Zahn 1999; Lino et al. 2015). Moreover, we found a higher proportion of reproductive females in warmer nurseries. Since higher roost temperatures may additionally result in a faster development of juveniles (Reiter 2004a), we suggest that reproductive females prefer warmer roosts in order to increase their reproductive success. In a given nursery, the number of individuals fluctuated in the present study, indicating that $R$. hipposideros uses a network of roosts during the maternity season. However, the number of pups born in a roost remained constant which confirmed that mothers stayed inside the same roost after parturition. Thus, in the present study, roost switching was either conducted by males, which have a higher 
affinity to change roosts (compare Downs et al. 2016), or by non-reproductive females. In contrast, studies from Central Europe showed roost switching of females with their pups, caused by changes in temperatures that where either too low (Kolb 1950; Lino et al. 2015) or too high (Kayikcioglu and Zahn 2004). This discrepancy may be accounted for by two facts: in our study, the temperature of $34{ }^{\circ} \mathrm{C}$ given in Kayikcioglu and Zahn (2004) was never exceeded in all parts of a given nursery so that bats could move to alternative perching sites (compare e.g. Weiner and Zahn 2000), and clustering of individuals may have been sufficient to compensate for lower temperatures. Indeed, clustering, known to act as an important strategy of thermoregulation (Roverud and Chappell 1991; Speakman and Thomas 2003), was correlated with lower temperatures before parturition started. The observed reduction of clustering after parturition, in turn, may reduce the risk that unfledged juveniles drop to the ground.

Our observations of nurseries confirmed their importance as night roosts (McAney and Fairley 1988; Zahn et al. 2008; Downs et al. 2016), particularly for reproductive females. The observed nightly returns of mothers with a pup of an age of less than a week created typical patterns of absence bouts, which we interpret as foraging bouts. They always showed an initial foraging bout after dusk and a last foraging bout before dawn. This may reflect an adaptation to peaks in prey abundance (Swift 1980; Rautenbach et al. 1988; Jones and Rydell 1994; Lino et al. 2015) which reproductive females will rely on to satisfy their energy budget during lactation. In total, mothers left the roost during about $50 \%$ of the night, which fits to studies from Central Europe (Kurta et al. 1989; Zahn et al. 2008). Since a short commuting distance ensures reproductive females an extended presence in their nursery, this underlines the need of closely located foraging areas and freshwater bodies as pointed out in previous studies (e.g., Mitchell-Jones 1995; Bontadina et al. 1997; Oakeley and Jones 1998; Russo et al. 2019). Buildings with a short commuting distance to these resources thus deserve special attention in conservation measures.

\section{Implications for protecting buildings}

In our study, Rhinolophus bats roosted predominantly in fairly intact buildings which had high evaluation scores based on their structure. However, lack of maintenance is a general problem of abandoned settlements; in the Asinara National Park, specifically, feral goats are inflicting damage on buildings when climbing on top of them. The building that contained the biggest colony on the island is actually in danger of collapse. To sustain abandoned infrastructure is thus a primary requirement for a long-term protection of bats, as only sustainably protected buildings provide a stable microclimate and can serve as roosts over several years. As microclimate differs between roost types, we recommend to protect the whole network of used buildings to allow roost switching according to the bats' life cycle. In our study, both species used a complex network of several buildings for different purposes, as suggested by Maltagliati et al. (2013) for $R$. ferrumequinum, including temporary day roosts which may provide alternatives if a colony loses a regular day roost. Nevertheless, our results showed that even a single building may contain several roost types for both species. The protection of these multiple roost providers may be particularly effective. An important factor favouring the use of buildings as roosts on Asinara may be the low amount of nightly illumination. Since artificial light illuminating roosts may hamper synanthropic roosting (e.g., Downs et al. 2003; Boldogh et al. 2007; Stone et al. 2015), this factor needs to be considered for roost management in general.

Further on, we recommend to improve protection measures against predators in buildings used by Rhinolophus bats. Our results indicate that favourably located buildings with limited access for predators were crucial factors for nurseries of $R$. hipposideros. Since stray cats, frequently encountered on Asinara as well as throughout Mediterranean regions, have been shown to be a main predator for bats in rural areas (Ancillotto et al. 2013), roost protection must include the prevention of cat access especially when buildings do not provide perching sites at higher ceilings. Day roosts may become more attractive as nursery roosts when entrances are carefully made smaller to exclude predators.

Our evaluation criteria were suitable to reliably exclude particular buildings as potential Rhinolophus roosts. However, about $75 \%$ of the buildings rated as "high potential" were also not used by Rhinolophus bats. Either the full roost potential of the island is not yet completely exploited so that these structures are left for future usage in case populations increase, or they may simply not be adequate for roosting due to unsuitable microclimatic conditions, or location far from foraging areas or freshwater supply. The microclimate of so far unused buildings with a high roost potential based on structural criteria should thus be monitored in future and, if necessary, modified to adjust microclimate as a conservation measure. As far as location is concerned, closely located forested areas have been identified as main factor for enhancing roosting sites for both Rhinolophus species (e.g., Reiter 2004b; Tournant et al. 2013; Froidevaux et al. 2017; Le Roux et al. 2017). However, only a small forested area is left in the northern part of Asinara whereas Macchia and Garrigue dominate the rest of the island (Fig. 1). Both Rhinolophus species have been detected in these Mediterranean landscapes (e.g., Russo and Jones 2003, Rainho 2007). Yet, we found no bigger colonies or nurseries of $R$. ferrumequinum. In contrast, $R$. hipposideros not only was a predominant species, but also used buildings in different parts on the island for its whole life 
cycle. This suggests that $R$. hipposideros is able to rely on other habitat types for foraging, whereas $R$. ferrumequinum may be highly dependent on forests.

In sum, the present study shows that structural characteristics of buildings supplemented by microclimatic data are suitable predictors for potential Rhinolophus roosts. A protection and adequate maintenance of abandoned buildings may thus constitute a promising tool for bat conservation in fragmented Mediterranean landscapes.

Acknowledgements We highly appreciated the personal contact to, and the interest of, Marianne Fischer. We especially thank the following persons who helped during field work and with input to our study design: Giovanni Careddu, Giomaria Deriu from the National Park Asinara, all members of the Agenzia Forestas, Robin Stadtmann, Tim Drissen, and Julia Treitler from the Asinara Project of the University Hildesheim and the motivated and interested students Hanna Graen, Iris Jacobsen, Jonathan Langenbusch, Linda Thierling, Marc Wätzold, and Vanessa Weske. We thank Dr. J. Pillat for providing custom-made software for picture analysis.

Funding information Open Access funding provided by Projekt DEAL. The funding for this study was provided by the Marianne und Dr. Fritz Walter Fischer Foundation of the "Deutsches Stiftungszentrum".

\section{Compliance with ethical standards}

Ethics statement All applicable international, national, and/or institutional guidelines for the care and use of animals were followed. All roost inspections were performed by a single person using red or weak white light, avoiding noises and staying as short as possible inside roosts to minimize disturbance for roosting bats. During the breeding season, nursery roosts were entered only once, after the outflight of the respective colony, for the maintenance of IR cameras. All surveys were made with permits from the National Park Asinara and the Italian Ministry of Environment (Prot. 0007542-20/04/2015-PNM-II).

Conflict of interest The authors declare that they have no conflict of interest.

Open Access This article is licensed under a Creative Commons Attribution 4.0 International License, which permits use, sharing, adaptation, distribution and reproduction in any medium or format, as long as you give appropriate credit to the original author(s) and the source, provide a link to the Creative Commons licence, and indicate if changes were made. The images or other third party material in this article are included in the article's Creative Commons licence, unless indicated otherwise in a credit line to the material. If material is not included in the article's Creative Commons licence and your intended use is not permitted by statutory regulation or exceeds the permitted use, you will need to obtain permission directly from the copyright holder. To view a copy of this licence, visit http://creativecommons.org/licenses/by/4.0/.

\section{References}

Ancillotto L, Serangeli MT, Russo D (2013) Curiosity killed the bat: domestic cats as bat predators. Mamm Biol 78:369-373

Avery MI (1985) Winter activity of pipistrelle bats. J Anim Ecol 54:721738
Barnosky AD, Matzke N, Tomiya S, Wogan GO, Swartz B, Quental TB, Mersey B (2011) Has the Earth's sixth mass extinction already arrived? Nature 471(7336):51

Boldogh S, Dobrosi D, Samu P (2007) The effects of the illumination of buildings on house-dwelling bats and its conservation consequences. Acta Chiropterol 9(2):527-534

Bontadina F, Hotz T, Gloor S, Beck A, Lutz M, Mühlethaler E (1997) Protection of feeding areas of Rhinolophus ferrumequinum. An action plan based on the results of a radiotraking study in an alpine valley of Switzerland. In: Arbeitskreis Fledermäuse Sachsen-Anhalt e.V (Ed.) - Tagungsband: Zur Situation der Hufeisennasen in Europa. IFA-Verlag. Berlin, pp 33-39

Bontadina F, Arlettaz R, Fankhauser T, Lutz M, Mühlethaler E, Theiler A, Zingg P (2000) The lesser horseshoe bat Rhinolophus hipposideros in Switzerland: present status and research recommendations. Le Rhinolophe 14:69-83

Bontadina F, Schofield H, Naef-Daenzer B (2002) Radio-tracking reveals that lesser horseshoe bats (Rhinolophus hipposideros) forage in woodland. J Zool 258(3):281-290

Daan S, Wichers HJ (1968) Habitat selection of bats hibernating in a limestone cave. Z Säugetierkd 33:262-287

DeCoursey G, DeCoursey PJ (1964) Adaptive aspects of activity rhythms in bats. Biol Bull 126(1):14-27

Dietz C, Kiefer A (2014) Die Fledermäuse Europas: kennen, bestimmen, schützen. Kosmos-Verlag, Stuttgart

Dietz C, Von Helversen O, Nill D (2007) Handbuch der Fledermäuse Europas und Nordwestafrikas. Franckh-Kosmos, Stuttgart

Downs NC, Beaton V, Guest J, Polanski J, Robinson SL, Racey PA (2003) The effects of illuminating the roost entrance on the emergence behaviour of Pipistrellus pygmaeus. Biol Conserv 111(2): 247-252

Downs NC, Cresswell WJ, Reason P, Sutton G, Wells D, Williams L, Wray S (2016) Activity patterns and use of night roosts by lesser horseshoe bats Rhinolophus hipposideros (Borkhausen, 1797). Acta Chiropterol 18(1):223-237

Duvergé PL, Jones G (1994) Greater horseshoe bats-activity, foraging behaviour and habitat use. British Wildlife 6:69-77

Fahrig L (2003) Effects of habitat fragmentation on biodiversity. Ann Rev Ecol Evol S 34(1):487-515

Fenton MB (1970) Population studies of Myotis lucifugus (Chiroptera: Vespertilionidae) in Ontario. Life Sci Contr R Ont Mus 77:1-34

Fenton MB, Taylor PJ, Jacobs DS, Richardson EJ, Bernard E, Bouchard S, Debaeremaeker KR, ter Hofstede H, Hollis L, Lausen CL, Lister JS, Rambaldini D, Ratcliffe JM, Reddy E (2002) Researching littleknown species: the African bat Otomops martiensseni (Chiroptera: Molossidae). Biodivers Conserv 11:1583-1606

Flanders J, Jones G (2009) Roost use, ranging behavior, and diet of greater horseshoe bats (Rhinolophus ferrumequinum) using a transitional roost. J Mammal 90(4):888-896

Froidevaux JSP, Boughey KL, Barlow KE, Jones G (2017) Factors driving population recovery of the greater horseshoe bat (Rhinolophus ferrumequinum) in the UK: implications for conservation. Biodivers Conserv 26(7):1601-1621

Gaisler J (1963) The ecology of the lesser horseshoe bat (Rhinolophus hipposideros) hipposideros (Bechstein, 1800) in Czechoslovakia II: ecological demands, problem of synantrophy. Vest csl Spol zool 27: $322-327$

Gaisler J (1966) Reproduction in the lesser horseshoe bat (Rhinolophus hipposideros hipposideros Bechstein, 1800). Bijdragen tot de Dierkunde 36(1):45-62

Grill A, Casula P, Leci R, Menken S (2007) Endemism in Sardinia. In: Weiss S, Ferrand N (eds) Phylogeography of southern European refugia. Springer, Dordrecht, pp 273-296

Hutson AM, Mickleburgh SP, Racey PA (2001) Microchiropteran bats: global status survey and conservation action plan. IUCN/SSC Chiroptera Specialist Group. IUCN, Switzerland and Cambridge 
Jones G, Rydell J (1994) Foraging strategy and predation risk as factors influencing emergence time in echolocating bats. Philos T Roy Soc B 346(1318):445-455

Kayikcioglu A, Zahn A (2004) High temperatures and the use of satellite roosts in Rhinolophus hipposideros. Mamm Biol 69(5):337-341

Knight T, Jones G (2009) Importance of night roosts for bat conservation: roosting behaviour of the lesser horseshoe bat Rhinolophus hipposideros. Endanger Species Res 8(1-2):79-86

Kolb A (1950) Beiträge zur Biologie einheimischer Fledermäuse. Zool. Jahrb. Abt. Syst. Oekol Geogr Tiere 78:547-572

Kunz TH (1982) Roosting ecology of bats. In: Kunz TH (ed) Ecology of bats. Springer, US, pp 1-55

Kunz TH, Reynolds DS (2003) Bat colonies in buildings. In: O'Shea TJ, Bogan MA (eds) Monitoring trends in bat populations of the United States and territories: problems and prospects. US Geological Survey, Biological Resources Division, Information and Technology Report, Washington, DC, pp 91-102

Kurta A, Bell GP, Nagy KA, Kunz TH (1989) Energetics of pregnancy and lactation in freeranging little brown bats (Myotis lucifugus). Physiol Zool 62(3):804-818

Le Roux M, Redon M, Archaux F, Long J, Vincent S, Luque S (2017) Conservation planning with spatially explicit models: a case for horseshoe bats in complex mountain landscapes. Landsc Ecol 32(5):1005-1021

Lino A, Fonseca C, Mendes G, Pereira MJR (2015) Roosting behaviour and phenology of the lesser horseshoe bat (Rhinolophus hipposideros) in a breeding colony in Sintra, Portugal. Galemys 27:1-12

Lisón F, Palazón JA, Calvo JF (2013) Effectiveness of the Natura 2000 network for the conservation of cave-dwelling bats in a Mediterranean region. Anim Conserv 16(5):528-537

Maltagliati G, Agnelli P, Cannicci S (2013) Where and at what time? Multiple roost use and emergence time in greater horseshoe bats (Rhinolophus ferrumequinum). Acta Chiropterol 15(1):113-120

Marnell F, Presetnik P (2010) Protection of overground roosts for bats. EUROBATS Publication Series No. 4 (English version). UNEP / EUROBATS Secretariat, Bonn, Germany, pp 1-57

Massida F (2008) The prison, lighthouse and sanitary station. In: Forteleoni C, Gazale V (eds) Asinara, National park - protected marine area. Carlo Delfino editore, Sassari, pp 67-82

Mazurska K, Ruczyński I (2008) Bats select buildings in clearings in Białowieża Primeval forest. Acta Chiropterol 10(2):331-338

McAney CM, Fairley JS (1988) Activity patterns of the lesser horseshoe bat Rhinolophus hipposideros at summer roosts. J Zool 216(2):325338

McNab BK (1974) The behavior of temperate cave bats in a subtropical environment. Ecology 55(5):943-958

Mitchell-Jones AJ (1995) The status and conservation of horseshoe bats in Britain. Myotis 32(33):271-284

Mucedda M, Pidinchedda E (2010) Pipistrelli in Sardegna - Conoscere e tutelare i mammiferi volanti. Nuova Stampa Color, Muros

Myers N, Mittermeier RA, Mittermeier CG, Da Fonseca GA, Kent J (2000) Biodiversity hotspots for conservation priorities. Nature 403(6772):853-858

Oakeley SF, Jones G (1998) Habitat around maternity roosts of the $55 \mathrm{kHz}$ phonic type of pipistrelle bats (Pipistrellus pipistrellus). J Zool 245(2):222-228

Ormsbee PC, Kiser J, Perlmeter SI (2007) The importance of night roosts to the ecology of forest bats. In: Lacki MJ, Hayes JP, Kurta A (eds) Bats in forests: conservation and management. John Hopkins University Press, Baltimore, pp 129-152

Park KJ, Jones G, Ransome RD (2000) Torpor, arousal and activity of hibernating greater horseshoe bats (Rhinolophus ferrumequinum). Funct Ecol 14(5):580-588

Piraccini R (2016) Rhinolophus ferrumequinum. The IUCN Red List of Threatened Species 2016: e.T19517A21973253. https://doi.org/10.
2305/IUCN.UK.2016-2.RLTS.T19517A21973253.en. Downloaded on 09 January 2020

Rainho A (2007) Summer foraging habitats of bats in a Mediterranean region of the Iberian Peninsula. Acta Chiropterol 9(1):171-181

Ransome RD (1968) The distribution of the greater horse-shoe bat, Rhinolophus ferrumequinum, during hibernation, in relation to environmental factors. J Zool 154:77-112

Ransome RD (1971) The effect of ambient temperature on the arousal frequency of the hibernating greater horseshoe bat, Rhinolophus fermmequinum, in relation to site selection and the hibernation state. J Zool 164:353-371

Rautenbach IL, Kemp AC, Scholtz CH (1988) Fluctuations in availability of arthropods correlated with microchiropteran and avian predator activities. Koedoe 31(1):77-90

Reiter G (2004a) Postnatal growth and reproductive biology of Rhinolophus hipposideros (Chiroptera: Rhinolophidae). J Zool 262(3):231-241

Reiter G (2004b) The importance of woodland for Rhinolophus hipposideros (Chiroptera, Rhinolophidae) in Austria. Mammalia 68(4):403-410

Reiter G, Pölzer E, Mixanig H, Bontadina F, Hüttmeir U (2013) Impact of landscape fragmentation on a specialised woodland bat, Rhinolophus hipposideros. Mamm Biol 78(4):283-289

Roverud RC, Chappell MA (1991) Energetic and thermoregulatory aspects of clustering behavior in the neotropical bat Noctilio albiventris. Physiol Zool 64(6):1527-1541

Russo D, Jones G (2003) Use of foraging habitats by bats in a Mediterranean area determined by acoustic surveys: conservation implications. Ecography 26:197-209

Russo D, Ancillotto L, Cistrone L, Libralato N, Domer A, Cohen S, Korine C (2019) Effects of artificial illumination on drinking bats: a field test in forest and desert habitats. Anim Conserv 22(2):124 133

Schofield HW (1996) The ecology and conservation biology of Rhinolophus hipposideros, the lesser horseshoe bat. $\mathrm{PhD}$ thesis, University of Aberdeen, Aberdeen, UK

Shiel CB, Shiel RE, Fairley JS (1999) Seasonal changes in the foraging behaviour of Leisler's bats (Nyctalus leisleri) in Ireland as revealed by radio-telemetry. J Zool 249:347-358

Speakman JR, Thomas DW (2003) Physiological ecology and energetics of bats. In: TH Kunz, Brock Fenton M (Eds.), Bat ecology. Univ. Chicago Press, Chicago, pp. 430-490

Stone EL, Harris S, Jones G (2015) Impacts of artificial lighting on bats: a review of challenges and solutions. Mamm Biol 80(3):213-219

Swift SM (1980) Activity patterns of pipistrelle bats (Pipistrellus pipistrellus) in north-east Scotland. J Zool 190:285-295

Taylor P (2016) Rhinolophus hipposideros. The IUCN Red List of Threatened Species 2016: e.T19518A21972794. https://doi.org/10. 2305/IUCN.UK.2016-2.RLTS.T19518A21972794.en. Downloaded on 09 January 2020

Tournant P, Afonso E, Roué S, Giraudoux P, Foltête JC (2013) Evaluating the effect of habitat connectivity on the distribution of lesser horseshoe bat maternity roosts using landscape graphs. Biol Conserv 164: 39-49

Twente JW (1955) Some aspects of habitat selection and other behavior of cavern-dwelling bats. Ecology 36(4):706-732

Voigt CC, Phelps KL, Aguirre LF, Schoeman MC, Vanitharani J, Zubaid A (2016) Bats and buildings: the conservation of synanthropic bats. In: Voigt CC, Kingston T (eds) Bats in the anthropocene. Springer, Cham, pp 427-462. https://doi.org/10.1007/978-3-319-25220-9_14

Walmsley B, Hodgson JA, Burke RE (1978) Forces produced by medial gastrocnemius and soleus muscles during locomotion in freely moving cats. J Neurophysiol 41(5):1203-1216

Walsh AL, Harris S (1996) Foraging habitat preferences of vespertilionid bats in Britain. J Appl Ecol 33(3):508-518 
Weiner P, Zahn A (2000) Roosting ecology, population development, emergence behaviour and diet of a colony of Rhinolophus hipposideros (Chiroptera: Rhinolophidae) in Bavaria. In: Proceedings of the VIIIth EBRS (Vol. 1, No. 231.242). Krakow: Chiropterological Information Center, Institute of Systematics and Evolution of Animals PAS

Winter R, Mucedda M, Pidinchedda E, Kierdorf U, Schmidt S, MantillaContreras J (2017) Small in size but rich in bats — species diversity and abandoned man-made structures put Asinara Island (Sardinia) into conservation focus for bats in the Mediterranean region. Acta Chiropterol 19(1):119-126

Zahn A (1999) Reproductive success, colony size and roost temperature in attic-dwelling bat Myotis myotis. J Zool 247:275-280
Zahn A, Holzhaider J, Kriner E, Maier A, Kayikcioglu A (2008) Foraging activity of Rhinolophus hipposideros on the island of Herrenchiemsee, Upper Bavaria. Mamm Biol 73(3):222-229

Zajac FE, Zomlefer MR, Levine WS (1981) Hindlimb muscular activity, kinetics and kinematics of cats jumping to their maximum achievable heights. J Exp Biol 91(1):73-86

Zukal J, Berková H, Řehák Z (2005) Activity and shelter selection by Myotis myotis and Rhinolophus hipposideros hibernating in the Kateřinská cave (Czech Republic). Mamm Biol 70(5):271-281

Publisher's note Springer Nature remains neutral with regard to jurisdictional claims in published maps and institutional affiliations. 